Article

\title{
Structural Connectivity-Based Parcellation of the Dopaminergic Midbrain in Healthy Subjects and Schizophrenic Patients
}

\author{
Gianpaolo Antonio Basile ${ }^{1, *}$, Alessia Bramanti ${ }^{2,+}$, Salvatore Bertino ${ }^{1, \dagger}$, Giuseppina Cutroneo ${ }^{1}$, \\ Antonio Bruno ${ }^{3}$, Adriana Tisano ${ }^{4}$, Giuseppe Paladina ${ }^{2}$, Demetrio Milardi ${ }^{1,2, *,+}$ and \\ Giuseppe Anastasi 1, + \\ 1 Brain Mapping Lab, Department of Biomedical, Dental Sciences and Morphological and Functional Images, \\ University of Messina, 98124 Messina, Italy; bertinosalvatore404@gmail.com (S.B.); \\ gcutroneo1@gmail.com (G.C.); dptbiosciences@gmail.com (G.A.) \\ 2 IRCCS Centro Neurolesi “Bonino Pulejo”, 98124 Messina, Italy; alebramanti@gmail.com (A.B.); \\ peppepaladina@hotmail.it (G.P.) \\ 3 Psychiatry Unit, Department of Biomedical and Dental Sciences and Morphological and Functional Imaging, \\ University of Messina, 98124 Messina, Italy; abruno@gmail.com \\ 4 Physical, Rehabilitation Medicine and Sport Medicine Unit, University Hospital G. Martino, \\ 98124 Messina, Italy; atisano@libero.it \\ * Correspondence: gbasile94@hotmail.it (G.A.B.); dmilardi@unime.it (D.M.); \\ Tel.: +39-0902217143 (G.A.B. \& D.M.) \\ + These authors contributed equally to this work.
}

Received: 30 September 2020; Accepted: 7 December 2020; Published: 10 December 2020

\begin{abstract}
Background and objectives: Functional deregulation of dopaminergic midbrain regions is a core feature of schizophrenia pathophysiology. Anatomical research on primates suggests that these regions may be subdivided into distinct, topographically organized functional territories according to their connectivity to the striatum. The aim of the present work was the reconstruction of dopaminergic midbrain subregions in healthy subjects and schizophrenic patients and the evaluation of their structural connectivity profiles. Materials and Methods: A hypothesis-driven connectivity-based parcellation derived from diffusion tractography was applied on 24 healthy subjects and 30 schizophrenic patients to identify distinct territories within the human dopaminergic midbrain in vivo and non-invasively. Results: We identified a tripartite subdivision of dopaminergic midbrain, including limbic, prefrontal and sensorimotor territories. No significant differences in structural features or connectivity were found between subjects and patients. Conclusions: The parcellation scheme proposed herein may help to achieve detailed characterization of structural and functional anomalies of the dopaminergic midbrain in schizophrenic patients.
\end{abstract}

Keywords: schizophrenia; midbrain; substantia nigra; diffusion weighted imaging tractography; ventral tegmental area; neuroimaging

\section{Introduction}

Schizophrenia (SZ) is a common, invalidating mental disease with a huge social and economical burden, with still unknown etiology and pathogenesis [1]. Among biological factors, deregulation of the dopaminergic system has been long-time implicated in the pathophysiology of the most common symptoms [2]. In light of the central role played by dopamine in brain systems regulating salience detection and attribution, it has been suggested that positive symptoms, such as delusions or hallucinations, could emerge as consequence of an aberrant attribution of salience to otherwise 
irrelevant elements of every-day life [3-5]. On the other hand, the effects of altered dopaminergic neurotransmission in terms of value representation, reward processing and reinforcement learning may underlie motivation-related negative symptoms such as anhedonia or abulia [6].

Substantia nigra pars compacta (SNc) and the nearby adjacent ventral tegmental area (VTA) are the most important dopaminergic brain regions implied in schizophrenia [7-10]. While traditionally these regions are often regarded as clearly distinct in functional terms, being SNc mostly implied in motor control [11,12] and VTA in salience and reward processing [13,14], a growing line of research suggests that these regions can be considered as being part of a unified "midbrain dopaminergic complex" [15-17] with topographically organized, cytoarchitectonically distinct functional territories. Studies in primate models demonstrated that midbrain dopaminergic neurons can be subdivided in three tiers according to their cytoarchitecture, connectivity and immunoreactivity pattern: (i) a ventro-lateral, calbindine-negative tier mostly connected to motor striatum; (ii) a densocellular, calbindine-negative, intermediate tier mostly connected to associative striatum; (iii) a dorso-medial, sparse-cells, calbindine-positive tier that is connected to limbic territories of dorsal striatum, ventral striatum and cortex [18-23].

It can be hypothesized that these different functional compartments within the human SNc/VTA may show selective functional or structural alterations in schizophrenic patients. However, to the best of our knowledge, only a few attempts have been made for differentiating distinct sub-territories of the human midbrain dopaminergic complex [24,25] and their role both in the healthy human brain $[26,27]$ and in schizophrenic patients [28] is still poorly understood.

In the present work, we employed structural and diffusion-weighted magnetic resonance imaging datasets from 24 healthy controls (HC) and 30 schizophrenic patients (SZ) from the Mind Clinical Imaging Consortium repository (MCICShare) [29-31] in order to evaluate topographically selective differences in structural connectivity of the dopaminergic midbrain complex. We adopt a two-step hypothesis-driven connectivity-based parcellation approach [32-34] based on multi-tissue constrained-spherical deconvolution (CSD) tractography $[35,36]$ to reconstruct distinct, topographically arranged territories within the human SNc/VTA according to midbrain-striatal connectivity. Then, we compared volumetric and structural connectivity differences within these territories between HCs and SZ patients.

\section{Materials and Methods}

\subsection{Patients and Controls Selection}

Data used in the preparation of this work were obtained from the Mind Clinical Imaging Consortium database through the Mind Research Network (www.mrn.org). The MCIC project was supported by the Department of Energy under Award Number DE-FG02-08ER64581. MCIC is the result of efforts of co-investigators from University of Iowa, University of Minnesota, University of New Mexico, Massachusetts General Hospital.

Dataset from $24 \mathrm{HCs}$ and $30 \mathrm{SZ}$ patients have been collected from the MCICShare repository. The two groups were matched for age (range 18-60 years) and sex (HC: 32 years \pm 11, 14 males, 10 females; SZ: 32 years $\pm 10,22$ males, 8 females). Inclusion criteria for the patient group was based on diagnostic criteria for schizophrenia, schizoaffective or schizophreniform disorders as defined in the fourth edition of Diagnostic and Statistic Manual for Mental Disorders (DSM-IV). The control group was composed of subjects with no history of actual or previous psychiatric disorders or substance dependence, including having received symptomatic treatment with antidepressant, anxiolytic or hypnotic drugs for more than 2 weeks and less than 6 months after the study.

Common exclusion criteria for patients and controls were: IQ lower than 70, as measured with a standardized test; clinical history of head trauma with prolonged loss of consciousness, neurosurgical intervention, neurological disease, severe or disabling diseases; contraindications to MRI scan such as gravedance or metal implants. 
Structural clinical interview for DSM-IV (SCID/SCID-NP for controls) and Comprensive Assessment of Symptoms and History (CASH) [37] have been used to evaluate clinical history and psychiatric symptoms in patients and controls. In patients, severity of positive and negative symptoms has been scored using the Scale for Assessment of Positive Symptoms (SAPS) and Scale for Assessment of Negative Symptoms (SANS), respectively [38,39]. Only one patient is neuroleptic-naive. Extrapyramidal symptoms have been assessed using the Simpson and Angus Scale (SAS) [40,41]. Demographic and clinical data related to patients and controls are resumed in Table 1.

Table 1. Demographic and clinical features of the sample.

\begin{tabular}{ccccc}
\hline & \multicolumn{2}{c}{ HC } & \multicolumn{3}{c}{ SZ } \\
\hline & Mean & StD & Mean & StD \\
\hline Age & 31.75 & 11.76 & 32.56 & 10.50 \\
Males & 14 & $/$ & 22 & $/$ \\
Females & 10 & $/$ & 8 & $/$ \\
Handedness (R/L/Both) & $23 / 1 / 0$ & $/$ & $26 / 3 / 1$ & $/$ \\
Mean Illness Duration (years) & $/$ & $/$ & 9.26 & 8.73 \\
Extrapyramidal Signs (SAS) & $/$ & $/$ & 2.39 & 2.79 \\
Negative Symptoms (SANS) & $/$ & $/$ & 7.21 & 2.81 \\
Positive Symptoms (SAPS) & $/$ & $/$ & 4.82 & 2.25 \\
Disorganized symptoms & $/$ & & 2.04 & 2.23 \\
(SAPS) & & & & \\
\hline
\end{tabular}

StD: standard deviation. R: right. L: left. SAS: Simpson and Angus Scale; SANS: Scale for Assessment of Negative Symptoms; SAPS: Scale for Assessment of Positive Symptoms.

\subsection{Data Acquisition}

Since data were collected from a multi-site study repository, only datasets acquired in the acquisition site $\mathrm{C}$ were considered, to ensure uniformity among technical and acquisition features. All data were collected on a 3T MRI scanner (Siemens Trio, Erlangen, Germany) with the following parameters: for T1-weighted structural scans, $\mathrm{TR}=2530 \mathrm{~ms}, \mathrm{TE}=3.79 \mathrm{~ms}, \mathrm{FA}=7$, bandwidth $=181$, voxel size $0.625 \times 0.625 \times 1.5 \mathrm{~mm}$; FOV matrix: $256 \times 256 \times 128 \mathrm{~mm}$; FOV $=16 \mathrm{~cm}$ (extended to $18 \mathrm{~cm}$ for whole brain coverage); for diffusion weighted imaging (DWI) scans, TR $=10,500 \mathrm{~ms}$, $\mathrm{TE}=98 \mathrm{~ms}$, b-values 0 and $1000 \mathrm{~s} / \mathrm{mm}^{2}$, voxel size $2 \times 2 \times 2 \mathrm{~mm}, \mathrm{NEX}=2$, band width $=1342,64$ slices, 12 directions [31].

\subsection{Data Preprocessing}

As a first step, T1 weighted images have been resampled to an isotropic voxel size of $1 \times 1$ $\times 1 \mathrm{~mm}$ using linear interpolation. DWI images underwent denoising and Gibbs ringing artifacts removal $[42,43]$ motion and Eddy Currents correction using the EDDY pipeline included in FMRIB Software Library (FSL) software [44]. Since no reverse phase encoding or fieldmap acquisition were available, geometric and susceptibility-weighted distortions were corrected by non-linear registration between B0 DWI image and T1-weighted structural image [45,46] using a mutual information inter-modal cost function [47]. This step has been implemented using Niftyreg [48]. The obtained transform was then applied to all DWI volumes with automatic gradient reorientation using the mrtransform utility featured in the MRtrix3 software [49]. Finally, DWI volumes underwent B1-field inhomogeneity correction [50]. All data were quality-checked by visually inspecting the outputs of each preprocessing step, in particular to ensure the accuracy of non-linear registration.

\subsection{Post-Processing}

T1-weighted images were skull-stripped [51] and underwent cortical and subcortical segmentation using FAST and FLIRT [50,52]; structural volumes were then non-linearly coregistered to Montreal 
Neurological Institute (MNI-152) standard brain template $\left(1 \mathrm{~mm}^{3}\right.$ resolution version) using FLIRT and FNIRT utilities on the FSL software [53] and direct and inverse transformations were saved.

Fractional anisotropy (FA) maps were obtained from preprocessed DWI volumes after tensor fitting and FA estimation using the commands dwi2tensor and tensor2metric featured in MRtrix3 software [54-56]. The CSD signal modeling was implemented by extracting a multi-tissue unsupervised response function directly from DWI single-shell scans [57].

Fiber orientation distribution (FOD) functions were then estimated using a super-resolved multi-tissue approach setting maximum spherical harmonic degree (lmax) to 8 , to take advantage of the hard non-negativity constraint of CSD when dealing with non-high-angular-resolution diffusion imaging (HARDI) data [36,58].

\subsection{Regions of Interest (ROI) Selection}

Cortical and subcortical regions of interest were extracted by non-linear registration to each subject's space of two standard-space atlases: Automated Atlas Labeling-v3 (AAL3) [59] for cortical parcellation and CIT68 Reinforcement Learning Atlas [60] for subcortical parcellation. The MNI-registered versions of these atlases were non-linearly coregistered to each subject's space using previously obtained inverse transformations between T1 scans and the MNI template. From subcortical parcellation, ROIs for caudate, putamen and nucleus accumbens on each side were merged to obtain a unified striatal seed ROI. For connectivity-based parcellation, cortical areas were merged into three target ROIs for each hemisphere: (i) a limbic group including orbitofrontal cortex, frontal pole, cingulate cortex and parahippocampal gyrus; (ii) a prefrontal group including the remaining dorsomedial, dorsolateral, ventromedial and ventrolateral prefrontal cortex; (iii) a sensorimotor group including supplementary motor area, precentral gyrus, postcentral gyrus and paracentral lobule. Since the DWI dataset has been previously non-linearly registered to $\mathrm{T} 1$ scans, each of these ROIs was checked for accurate localization on DWI volumes and, if needed, manually corrected by a trained neuroanatomist.

For what concerns ROIs of the dopaminergic SNc/VTA complex, since the correction of susceptibility-weighted artifacts based on registration to T1-weighted scans was not sufficient to ensure a correct registration of midbrain regions, that are usually more affected by such artifacts [44], we adopted a manual delineation strategy involving custom, study-specific FOD templates. FOD maps were intensity normalized and a study-specific template was obtained by iterating a symmetric, unbiased FOD registration algorithm which includes FOD reorientation using apodised delta functions [61-63] using the dedicated MrTrix 3 commands. To account for possible differences between patients and controls, two population templates were obtained from healthy subjects and schizophrenic patients, respectively. The dopaminergic midbrain complex was identified as a region of hypointensity located in the ventral midbrain anteriorly to the red nucleus, posteriorly to the crus cerebri and inferior to the subthalamic nucleus (Figure 1).

\subsection{Connectivity-Based Parcellation and Tractography}

To parcellate an SNc/VTA ROI according to its striatal connectivity, a two-step hypothesis driven parcellation approach was implemented [64]: as a first step, striatum was subdivided into limbic, prefrontal and sensorimotor territories according to cortico-striatal connectivity; then, connectivity between these functional territories and the $\mathrm{SNc} / \mathrm{VTA}$ ROIs was reconstructed and a second connectivity based-parcellation was performed on SNc/VTA ROIs. The common pipeline used for connectivity-based parcellation involved:

1. Seed-based tractography: 5000 streamlines were reconstructed seeding from seed ROIs (striatum, SNc/VTA) to the ipsilateral target ROIs (cortical groups) with the following parameters: algorithm IFod2 [65] step size 1.25, maximum angle 30. Target ROIs were used as inclusion mask; streamlines reaching each of the target masks were counted as connecting the source voxel to that target, and then immediately terminated. No exclusion masks were employed. 
2. Tractogram-to-voxel mapping: by applying the track-density-imaging (TDI) framework, each tractogram was mapped to an image in which intensity is defined as the number of streamlines passing through a given grid element [66], corresponding in dimension and voxel size to seed ROI; track-density streamline maps were then multiplied to binarized seed ROIs to obtain tractograms endpoint distribution.

3. Classification: each map obtained from the previous step was normalized by dividing each voxel's intensity to the mean intensity of the map, in order to obtain comparable intensity values: then, each voxel in the seed ROI was classified using a hard segmentation algorithm (find_the_biggest command on FSL) that assigns it to the map showing higher intensity.

4. Maximum probability maps reconstruction: for visualization purposes, each individual map was non-linearly coregistered to the corresponding study-specific FOD templates, binarized and summed up across the whole group to obtain maximum probability maps of each parcel at the group level. A threshold of $50 \%$ percent was assigned to show only voxels overlapping in at least half of the sample.

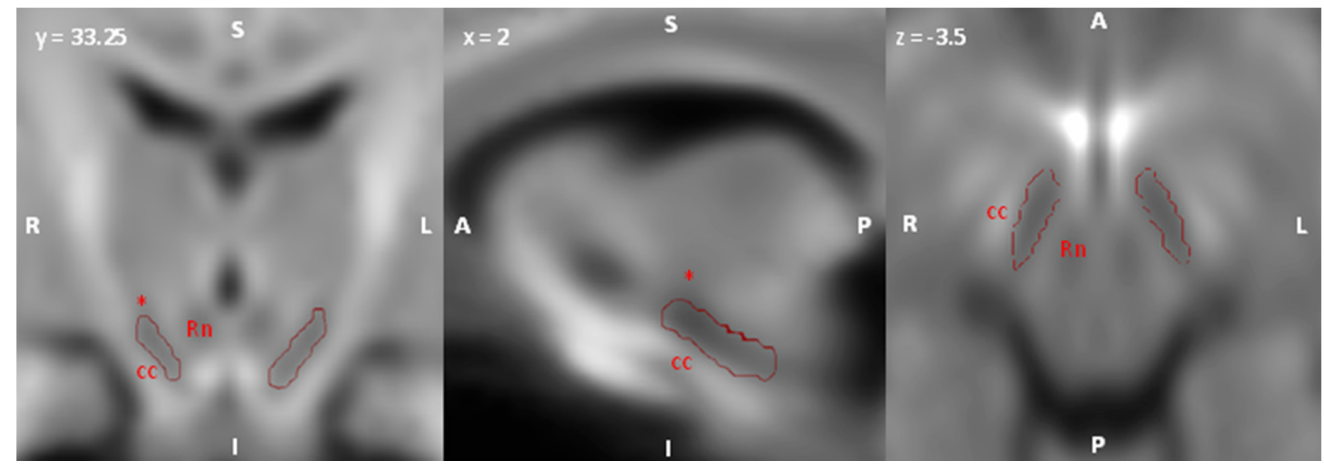

Figure 1. Identification of the Substantia nigra pars compacta (SNc)/ventral tegmental area (VTA) complex on study-specific fiber orientation distribution (FOD) template. Axial, sagittal and coronal sections showing the putative boundaries of SNc/VTA complex. SNc/VTA region was defined as an area of marked hypointensity situated anteriorly to the red nucleus (Rn), posteriorly to the crus cerebri (cc) and inferiorly to the subthalamic nucleus $\left({ }^{*}\right)$. S: superior; I; inferior; R: right; L: left; A: anterior; P: posterior.

The obtained SNc/VTA ROIs were then transformed back to each subject's native space, visually checked for correct localization on $\mathrm{B} 0$ and FOD images and manually corrected if needed.

\subsection{Quantitative Analysis}

To evaluate structural features of SNc/VTA and striatal parcellation in HC vs. SZ, different quantitative measures were estimated. Streamline density index (SDI) [32,67-69] was obtained from volumes of each striatal and SNc/VTA parcel at subject-level using the following formula:

$$
S D I=\frac{v_{\text {parcel }}}{V_{\text {seed }}} \times 100
$$

where $v_{\text {parcel }}$ is the volume of each connectivity-based parcel and $V_{\text {seed }}$ the volume of the corresponding seed ROI.

In addition, we sampled mean FA values along 10,000 streamlines randomly seeded from each SNc/VTA parcel (parameters: algorithm IFod2, step size 1.25, maximum angle 30). To evaluate group-level differences, each of these quantitative estimates (SDI from SNc/VTA parcellation and FA from SNc/VTA parcel connectivity) was fitted into a general linear model (GLM) with a three-way ANOVA design, setting side and parcel type (Limbic, Prefrontal and Sensorimotor) and diagnosis 
(HC or SZ) as independent variables. Post-hoc tests were adjusted for multiple comparisons using Bonferroni's test (significant $\alpha$ level $<0.05$ ). All statistical analysis was conducted using IBM SPSS Statistics, v25 (IBM Corporation, Armonk, NY, USA).

\section{Results}

The results from connectivity-based parcellation of striatum and SNc/VTA are depicted in Figure 2.

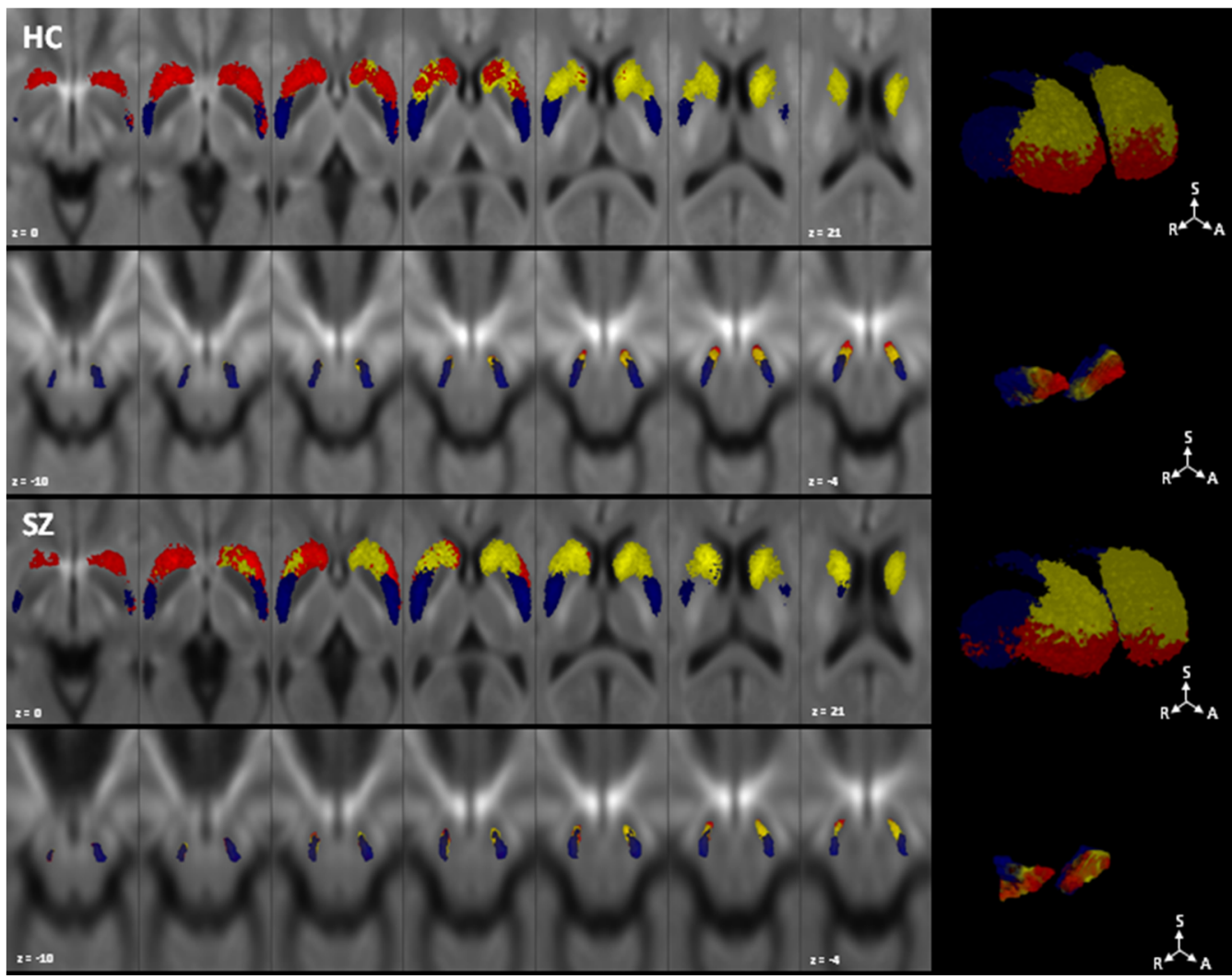

Figure 2. Topographical organization of SNc/VTA complex (lower row) according to striatal connectivity-based parcellation (upper row). Maximum probability maps showing only voxels overlapping in at least half of the sample are overlaid on study-specific FOD templates. Healthy controls are shown in the first two rows, and schizophrenic patients in the latter. Parcels mostly connected to the limbic cortex are colored in red, parcels with higher connectivity to prefrontal cortex are shown in yellow and parcels with higher connectivity to sensorimotor cortex are depicted in blue. 2D images are shown in radiological convention. HC: healthy controls; SZ: schizophrenic patients; S: superior; R: right; A: anterior.

For both striatal and SNc/VTA parcellation, all parcels were obtained in $100 \%$ of subjects, and all parcels showed at least one voxel overlapping between subjects in at least $50 \%$ of the sample (12/24 for HC, 15/30 for SZ). Striatal parcellation is arranged with a ventro-dorsal and antero-posterior gradient, with the limbic cluster occupying mainly the nucleus accumbens and the most ventral part of caudate and putamen, the prefrontal cluster located in the dorsal anterior part of the caudate and putamen and the sensorimotor cluster that spreads over the posterior portion of putamen and to a lesser extent to the dorsal portion of caudate. In comparison, SNc/VTA parcellation shows a medio-lateral and antero-posterior topographical arrangement, with an anterior and dorsal-limbic territory, an intermediate and ventral prefrontal territory and a posterolateral sensorimotor territory.

Table 2 shows the mean values for striatal and SNc/VTA SDI and FA from connectivity analysis. For striatal parcellation, three-way ANOVA revealed significant effects of side $(\mathrm{F}(1,312)=164.761, p<$ $\left.0.01, \eta^{2}=0.346\right)$, parcel $\left(\mathrm{F}(2,312)=126.359, p<0.01, \eta^{2}=0.448\right)$ and side $\times$ parcel interactions $(\mathrm{F}(2,312)=$ 
101.646, $\left.p<0.01, \eta^{2}=0.95\right)$. Post-hoc analysis for parcel resulted in significant differences between both sensorimotor and limbic (mean difference $=3.52, p<0.01$ ), limbic and prefrontal (mean difference $=2.92$, $p<0.01$ ) and prefrontal and sensorimotor parcels (mean difference $=6.54 ; p<0.01$ ). In addition, striatal parcellation reported significative SDI differences between the left and right side for most of parcels in both controls and patients with higher SDI values in the right sides for limbic clusters, (mean difference $=7.872, p<0.01$ ) and for prefrontal clusters (mean difference $=7.508, p<0.01$ ), while higher SDI values are in the left side for sensorimotor clusters (mean difference $=2.456, p<0.01$ ); no significant effects were found for diagnosis and its possible interactions.

Table 2. Mean values for striatal and SNc/VTA streamline density index (SDI) and fractional anisotropy (FA) from SNc/VTA parcel connectivity analysis. StD: standard deviation.

\begin{tabular}{|c|c|c|c|c|c|c|c|c|}
\hline & & & \multicolumn{2}{|c|}{ Striatal SDI } & \multicolumn{2}{|c|}{ SNc/VTA SDI } & \multicolumn{2}{|c|}{ FA } \\
\hline & & & Mean & StD & Mean & StD & Mean & StD \\
\hline \multirow{4}{*}{ Limbic } & \multirow{2}{*}{$\mathrm{HC}$} & Left & 32.020 & 3.83 & 23.922 & 9.999 & 0.467 & 0.050 \\
\hline & & Right & 39.671 & 3.39 & 27.298 & 7.225 & 0.468 & 0.058 \\
\hline & \multirow{2}{*}{$\mathrm{SZ}$} & Left & 30.902 & 3.24 & 22.016 & 8.494 & 0.438 & 0.139 \\
\hline & & Right & 38.903 & 2.03 & 26.889 & 10.791 & 0.436 & 0.146 \\
\hline \multirow{4}{*}{ Prefrontal } & \multirow{2}{*}{$\mathrm{HC}$} & Left & 24.725 & 1.95 & 26.050 & 11.162 & 0.474 & 0.047 \\
\hline & & Right & 32.462 & 2.9 & 23.838 & 8.271 & 0.436 & 0.146 \\
\hline & \multirow{2}{*}{$\mathrm{SZ}$} & Left & 25.503 & 2.03 & 29.570 & 7.817 & 0.488 & 0.061 \\
\hline & & Right & 32.78 & 3.21 & 28.228 & 12.131 & 0.440 & 0.144 \\
\hline \multirow{4}{*}{ Sensorimotor } & \multirow{2}{*}{$\mathrm{HC}$} & Left & 34.171 & 3.71 & 44.516 & 11.582 & 0.477 & 0.045 \\
\hline & & Right & 30.121 & 2.22 & 41.457 & 12.972 & 0.487 & 0.050 \\
\hline & \multirow{2}{*}{$\mathrm{SZ}$} & Left & 31.932 & 3.68 & 43.388 & 9.056 & 0.445 & 0.140 \\
\hline & & Right & 31.131 & 2.25 & 36.982 & 11.084 & 0.447 & 0.149 \\
\hline
\end{tabular}

SNc/VTA parcellation showed also a significant effect of parcel type $\left(\mathrm{F}(2,312)=84.485, p<0.01, \eta^{2}\right.$ $=0.351)$ and sidexparcel interactions $\left(\mathrm{F}(2,312)=5.232, p<0.01, \eta^{2}=0.032\right)$. Post-hoc analysis for parcel revealed significant differences between limbic and sensorimotor clusters (mean difference $=16.43$, $p<0.01$ ) and prefrontal and sensorimotor clusters (mean difference $=14.28, p<0.01$ ), but not between limbic and prefrontal parcels. In particular, limbic cluster have significantly higher values on the right side (mean difference $=4.125, p=0.037$ ), while sensorimotor clusters show significantly higher values on the left side (mean difference $=4.73, p=0.017$ ). Again, no significant effects were found for diagnosis and related interactions.

For FA analysis, three-way ANOVA revealed no significant main effects of side and parcel, but a trend toward significance was found for the main effect of diagnosis $(\mathrm{F}=8.116 ; p=0.05)$, with $\mathrm{SZ}$ patients exhibiting slightly lower FA values (mean difference $=0.036$ ). No significant interactions with side or parcels were found.

\section{Discussion}

In the present study we demonstrate that, in both HC and SZ patients, a similar topographical organization of connectivity between cerebral cortex, striatum and dopaminergic midbrain regions can be identified. In line with primate models of striatal organization [70,71] and with other neuroimaging investigations in the human brain [26,72], we found a ventral vs. dorsal topographical organization of cortico-striatal connectivity, with ventral striatal regions mostly connected to limbic cortical targets such as orbitofrontal and anterior cingulate cortex. The anterodorsal caudate and putamen are mostly connected to associative prefrontal regions, while sensorimotor cortical connectivity preferentially involves the dorsal caudate and putamen. We also show that a similar topographical organization is reflected in midbrain-striatal connectivity patterns, that show a medio-lateral topography with medial portions mostly connected to limbic striatum and lateral portions mostly connected to sensorimotor striatum, while associative striatum occupies an intermediate portion. To our knowledge, just a few neuroimaging studies of the human brain assessed the topographic organization of 
midbrain dopaminergic regions. An earlier investigation based on diffusion imaging [24] found a similar medio-lateral organization of connectivity, with medial SN mainly connected to ventral striatum and lateral SN mostly connected to the dorsal striatum. A recent investigation applied an unsupervised clustering algorithm to whole brain connectivity of SN and found three clusters with similar topographical organization [25]. In the current work, we extend the analysis to the SNc/VTA region of interest as defined by a recent multi-contrast MRI atlas [60]; plus, we opted for a two-step hypothesis-driven parcellation approach, in order to directly test the hypothesis about topographical organization derived from primate anatomical studies. The above described connectivity patterns partially reflect the functional organization of dopaminergic striatal circuitry described in primate models [19,21-23,73], although a clearly-described ventro-dorsal organization pattern could not be identified. While this could be in part conditioned by all the intrinsic limitations of tractography, that is not able to identify neuronal terminations at the synaptic level [74,75], the good agreement with animal findings support the hypothesis of a tripartite SNc/VTA subdivision in the human brain. These distinct topographical regions may play a crucial role in integrating different aspects of behavioral response to salient stimuli, from salience detection to finalized motor responses, incentive learning and habit formation [20].

In addition, our results suggest that such topographical organization could be maintained without relevant structural alterations in SZ patients, as we failed to find significative differences in SDI of both striatal and midbrain parcellation between patients and controls. In SZ patients, alterations in the functional activation of SNc/VTA in response to salient stimuli is well-documented from different functional MRI investigations [7,76,77]. It has been suggested that alteration in structural connectivity of the dopaminergic midbrain, in particular between SNc/VTA and prefrontal cortical regions, could explain these functional abnormalities [8-10,78]. To test this hypothesis, we extracted mean FA, that is commonly used as a surrogate measure of white matter structural integrity in SZ patients [79-81], from a sample of tractograms randomly seeded from each midbrain parcel. While we found slightly decreased FA values along midbrain-related white matter pathways, in line with recent research [82], we were not able to identify topographically specific alterations in midbrain connectivity. However, these results should be taken with a grain of salt and should be interpreted with care as they suffer from several limitations. First, they are based on a relatively small sample of subjects and patients and this may inherently reduce the statistical power of the analysis. Furthermore, they have been obtained from legacy data that do not correspond to modern standards for what concerns data acquisition; in particular, this work relies on low quality diffusion data (single shell datasets with low resolution, directions and b-values, no reverse phase encoding available); this features may have an influence on tractography results, despite they show a relatively good agreement with a previous work employing high quality data [25]. Due to the heterogeneous nature of the DWI preprocessing pipeline, we carefully inspected each output, in particular to ensure the good quality of non-linear registrations. In addition, we only evaluated FA from tractograms passing through SNc/VTA parcels, and we did not evaluated FA from specific targeted brain pathway (e.g., between SNc/VTA and different cortical regions) or adopting a voxel-wise approach. Finally, despite its popularity, the anatomical-pathological underpinnings of FA as a measure of white matter integrity are still far from being understood $[83,84]$.

\section{Conclusions}

In the present work, we described a tripartite parcellation of dopaminergic midbrain regions according to their structural connectivity to striatal territories. We found that this topographical organization is maintained in both HC and SZ patients with no significant differences. We suggest that the midbrain parcellation scheme proposed herein may be helpful to achieve a more effective characterization of structural and functional anomalies of the dopaminergic midbrain in SZ patients. We hope that the present work may act as a trigger for further research leading to a better understanding of the complex pathophysiology of SZ. 
Author Contributions: Conceptualization, G.A.B. and S.B.; supervision, formal analysis, A.B. (Alessia Bramanti); investigation, G.A.B.; resources, G.P.; data curation, G.C., A.T.; writing-original draft preparation, G.A.B.; writing-review and editing, A.B. (Alessia Bramanti), D.M., G.A.; visualization, A.B. (Antonio Bruno); project administration, D.M., G.A. All authors have read and agreed to the published version of the manuscript.

Funding: This research received no external funding.

Acknowledgments: The imaging data and demographic information were collected and shared by University of Iowa, University of Minnesota, University of New Mexico, Massachusetts General Hospital, the Mind Research Network supported by the Department of Energy under Award Number DE-FG02-08ER64581.

Conflicts of Interest: The authors declare no conflict of interest.

\section{References}

1. Van Os, J.; Kapur, S. Schizophrenia. Lancet 2009, 374, 635-645. [CrossRef]

2. Weinberger, D.R. Implications of Normal Brain Development for the Pathogenesis of Schizophrenia. Arch. Gen. Psychiatry 1987, 44, 660-669. [CrossRef] [PubMed]

3. Howes, O.D.; Nour, M.M. Dopamine and the aberrant salience hypothesis of schizophrenia. World Psychiatry 2016, 15, 3-4. [CrossRef] [PubMed]

4. Kapur, S. Psychosis as a State of Aberrant Salience: A Framework Linking Biology, Phenomenology, and Pharmacology in Schizophrenia. Am. J. Psychiatry 2003, 160, 13-23. [CrossRef] [PubMed]

5. Kapur, S.; Mizrahi, R.; Li, M. From dopamine to salience to psychosis-Linking biology, pharmacology and phenomenology of psychosis. Schizophr. Res. 2005, 79, 59-68. [CrossRef]

6. Strauss, G.P.; Waltz, J.A.; Gold, J.M. A Review of Reward Processing and Motivational Impairment in Schizophrenia. Schizophr. Bull. 2013, 40, S107-S116. [CrossRef]

7. Murray, G.K.; Corlett, P.R.; Clark, L.; Pessiglione, M.; Blackwell, A.D.; Honey, G.; Jones, P.B.; Bullmore, E.T.; Robbins, T.W.; Fletcher, P.C. Substantia nigra/ventral tegmental reward prediction error disruption in psychosis. Mol. Psychiatry 2007, 13, 267-276. [CrossRef]

8. Yoon, J.H.; Westphal, A.J.; Minzenberg, M.J.; Niendam, T.; Ragland, J.D.; Lesh, T.; Solomon, M.; Carter, C.S. Task-evoked substantia nigra hyperactivity associated with prefrontal hypofunction, prefrontonigral disconnectivity and nigrostriatal connectivity predicting psychosis severity in medication naïve first episode schizophrenia. Schizophr. Res. 2014, 159, 521-526. [CrossRef]

9. Yoon, J.H.; Minzenberg, M.J.; Raouf, S.; D’Esposito, M.; Carter, C.S. Impaired Prefrontal-Basal Ganglia Functional Connectivity and Substantia Nigra Hyperactivity in Schizophrenia. Biol. Psychiatry 2013, 74, 122-129. [CrossRef]

10. White, D.M.; Kraguljac, N.V.; Reid, M.A.; Lahti, A.C. Contribution of substantia nigra glutamate to prediction error signals in schizophrenia: A combined magnetic resonance spectroscopy/functional imaging study. NPJ Schizophr. 2015, 1, 14001. [CrossRef]

11. Vaillancourt, D.E.; Spraker, M.B.; Prodoehl, J.; Abraham, I.; Corcos, D.M.; Zhou, X.J.; Comella, C.L.; Little, D.M. High-resolution diffusion tensor imaging in the substantia nigra of de novo Parkinson disease. Neurology 2009, 72, 1378-1384. [CrossRef] [PubMed]

12. Damier, P.; Hirsch, E.C.; Agid, Y.; Graybiel, A.M. The substantia nigra of the human brain. Brain 1999, 122, 1421-1436. [CrossRef] [PubMed]

13. Goschke, T.; Bolte, A. Emotional modulation of control dilemmas: The role of positive affect, reward, and dopamine in cognitive stability and flexibility. Neuropsychologia 2014, 62, 403-423. [CrossRef] [PubMed]

14. Morales, M.; Margolis, E.B. Ventral tegmental area: Cellular heterogeneity, connectivity and behaviour. Nat. Rev. Neurosci. 2017, 18, 73-85. [CrossRef]

15. Düzel, E.; Bunzeck, N.; Guitart-Masip, M.; Düzel, S. NOvelty-related Motivation of Anticipation and exploration by Dopamine (NOMAD): Implications for healthy aging. Neurosci. Biobehav. Rev. 2010, 34, 660-669. [CrossRef]

16. Krebs, R.M.; Schott, B.H.; Düzel, E. Personality Traits Are Differentially Associated with Patterns of Reward and Novelty Processing in the Human Substantia Nigra/Ventral Tegmental Area. Biol. Psychiatry 2009, 65, 103-110. [CrossRef] 
17. D'Ardenne, K.; Eshel, N.; Luka, J.; Lenartowicz, A.; Nystrom, L.E.; Cohen, J.D. Role of prefrontal cortex and the midbrain dopamine system in working memory updating. Proc. Natl. Acad. Sci. USA 2012, 109, 19900-19909. [CrossRef]

18. Haber, S.N.; Ryoo, H.; Cox, C.; Lu, W. Subsets of midbrain dopaminergic neurons in monkeys are distinguished by different levels of mRNA for the dopamine transporter: Comparison with the mRNA for the D2 receptor, tyrosine hydroxylase and calbindin immunoreactivity. J. Comp. Neurol. 1995, 362, 400-410. [CrossRef]

19. Haber, S.N.; Knutson, B. The Reward Circuit: Linking Primate Anatomy and Human Imaging. Neuropsychopharmacology 2010, 35, 4-26. [CrossRef]

20. Haber, S.N.; Behrens, T.E. The Neural Network Underlying Incentive-Based Learning: Implications for Interpreting Circuit Disruptions in Psychiatric Disorders. Neuron 2014, 83, 1019-1039. [CrossRef]

21. Haber, S.N. The place of dopamine in the cortico-basal ganglia circuit. Neuroscience 2014, 282, $248-257$. [CrossRef] [PubMed]

22. Lynd-Balta, E.; Haber, S. The organization of midbrain projections to the striatum in the primate: Sensorimotor-related striatum versus ventral striatum. Neuroscience 1994, 59, 625-640. [CrossRef]

23. Haber, S.N.; Fudge, J.L.; McFarland, N.R. Striatonigrostriatal Pathways in Primates Form an Ascending Spiral from the Shell to the Dorsolateral Striatum. J. Neurosci. 2000, 20, 2369-2382. [CrossRef] [PubMed]

24. Chowdhury, R.; Lambert, C.; Dolan, R.J.; Düzel, E. Parcellation of the human substantia nigra based on anatomical connectivity to the striatum. Neuroimage 2013, 81, 191-198. [CrossRef] [PubMed]

25. Zhang, Y.; Larcher, K.; Misic, B.; Dagher, A. Anatomical and functional organization of the human substantia nigra and its connections. eLife 2017, 6, e26653. [CrossRef] [PubMed]

26. Tziortzi, A.C.; Haber, S.N.; Searle, G.E.; Tsoumpas, C.; Long, C.J.; Shotbolt, P.; Douaud, G.; Jbabdi, S.; Behrens, T.E.J.; Rabiner, E.A.; et al. Connectivity-Based Functional Analysis of Dopamine Release in the Striatum Using Diffusion-Weighted MRI and Positron Emission Tomography. Cereb. Cortex 2014, 24, 1165-1177. [CrossRef]

27. Mamiya, P.C.; Richards, T.; Corrigan, N.M.; Kuhl, P.K. Strength of Ventral Tegmental Area Connections With Left Caudate Nucleus Is Related to Conflict Monitoring. Front. Psychol. 2020, 10. [CrossRef]

28. Gunn, R.N.; Jenkinson, M.; Rabinner, E.A.; Behrens, T.; Shotbolt, P.; Long, C.; Tsoumpas, C.; Searle, G.; Haber, S.; Tziortzi, A. Quantification of dopamine release within the connectivity-derived functional subdivision of striatum. J. Cereb. Blood Flow Metab. 2012, 32, S166.

29. Wang, L.; Alpert, K.I.; Calhoun, V.D.; Cobia, D.J.; Keator, D.B.; King, M.D.; Kogan, A.; Landis, D.; Tallis, M.; Turner, M.D.; et al. SchizConnect: Mediating neuroimaging databases on schizophrenia and related disorders for large-scale integration. Neuroimage 2016, 124, 1155-1167. [CrossRef]

30. Wang, L.; Alpert, K.; Calhoun, V.; Keator, D.; King, M.; Kogan, A. Schizconnect: A one-stop web-based resource for large-scale schizophrenia neuroimaging data integration. Schizophr. Bull. 2015, 41. [CrossRef]

31. Gollub, R.L.; Shoemaker, J.M.; King, M.D.; White, T.; Ehrlich, S.; Sponheim, S.R.; Clark, V.P.; Turner, J.A.; Mueller, B.A.; Magnotta, V.; et al. The MCIC collection: A shared repository of multi-modal, multi-site brain image data from a clinical investigation of schizophrenia. Neuroinformatics 2013, 11, 367-388. [CrossRef] [PubMed]

32. Cacciola, A.; Milardi, D.; Bertino, S.; Basile, G.A.; Calamuneri, A.; Chillemi, G.; Rizzo, G.; Anastasi, G.; Quartarone, A. Structural connectivity-based topography of the human globus pallidus: Implications for therapeutic targeting in movement disorders. Mov. Disord. 2019, 34, 987-996. [CrossRef] [PubMed]

33. Cacciola, A.; Milardi, D.; Basile, G.A.; Bertino, S.; Calamuneri, A.; Chillemi, G.; Paladina, G.; Impellizzeri, F.; Trimarchi, F.; Anastasi, G.; et al. The cortico-rubral and cerebello-rubral pathways are topographically organized within the human red nucleus. Sci. Rep. 2019, 9, 1-12. [CrossRef]

34. Eickhoff, S.B.; Ethirion, B.; Varoquaux, G.; Bzdok, D. Connectivity-based parcellation: Critique and implications. Hum. Brain Mapp. 2015, 36, 4771-4792. [CrossRef] [PubMed]

35. Tournier, J.-D.; Yeh, C.-H.; Calamante, F.; Cho, K.-H.; Connelly, A.; Lin, C. Resolving crossing fibres using constrained spherical deconvolution: Validation using diffusion-weighted imaging phantom data. Neuroimage 2008, 42, 617-625. [CrossRef]

36. Jeurissen, B.; Tournier, J.-D.; Dhollander, T.; Connelly, A.; Sijbers, J. Multi-tissue constrained spherical deconvolution for improved analysis of multi-shell diffusion MRI data. Neuroimage 2014, 103, 411-426. [CrossRef] 
37. Andreasen, N.C.; Flaum, M.; Arndt, S. The Comprehensive Assessment of Symptoms and History (CASH). Arch. Gen. Psychiatry 1992, 49, 615-623. [CrossRef]

38. Andreasen, N.; Grove, W. Positive and Negative Symptoms in Schizophrenia. Psychiatr. Psychobiol. 1986, 1, 108-121. [CrossRef]

39. Andreasen, N.C. Scale for the Assessment of Negative Symptoms (SANS). Br. J. Psychiatry 1989, 155, 49-52. [CrossRef]

40. Simpson, G.M.; Angus, J.W.S. A Rating Scale for Extrapyramidal Side Effects. Acta Psychiatr. Scand. 1970, 45, 11-19. [CrossRef]

41. Barnes, T.R.E. A Rating Scale for Drug-Induced Akathisia. Br. J. Psychiatry 1989, 154, 672-676. [CrossRef] [PubMed]

42. Kellner, E.; Dhital, B.; Kiselev, V.G.; Reisert, M. Gibbs-ringing artifact removal based on local subvoxel-shifts. Magn. Reson. Med. 2016, 76, 1574-1581. [CrossRef] [PubMed]

43. Veraart, J.; Novikov, D.S.; Christiaens, D.; Ades-Aron, B.; Sijbers, J.; Fieremans, E. Denoising of diffusion MRI using random matrix theory. Neuroimage 2016, 142, 394-406. [CrossRef] [PubMed]

44. Andersson, J.L.R.; Sotiropoulos, S.N. An integrated approach to correction for off-resonance effects and subject movement in diffusion MR imaging. Neuroimage 2016, 125, 1063-1078. [CrossRef] [PubMed]

45. Bhushan, C.; Haldar, J.P.; Joshi, A.A.; Leahy, R.M. Correcting susceptibility-induced distortion in diffusion-weighted $\{\mathrm{MRI}\}$ using constrained nonrigid registration. IEEE Trans Signal Inf Process 2012. [CrossRef]

46. Gholipour, A.; Kehtarnavaz, N.; Gopinath, K.; Briggs, R.W.; Devous, M.D.; Haley, R.W. Distortion Correction via Non-rigid Registration of Functional to Anatomical Magnetic Resonance Brain Images. In Proceedings of the 2006 International Conference on Image Processing, Atlanta, GA, USA, 8-11 October 2006.

47. Maes, F.; Collignon, A.; Vandermeulen, D.; Marchal, G.; Suetens, P. Multimodality image registration by maximization of mutual information. IEEE Trans. Med. Imaging 1997, 16, 187-198. [CrossRef]

48. Modat, M.; Cash, D.M.; Daga, P.; Winston, G.P.; Duncan, J.S.; Ourselin, S. Global image registration using a symmetric block-matching approach. J. Med. Imaging 2014, 1, 024003. [CrossRef]

49. Tournier, J.D.; Smith, R.; Raffelt, D.; Tabbara, R.; Dhollander, T.; Pietsch, M.; Christiaens, D.; Jeurissen, B.; Yeh, C.-H.; Connelly, A. MRtrix3: A fast, flexible and open software framework for medical image processing and visualisation. Neuroimage 2019, 202, 116137. [CrossRef]

50. Zhang, Y.; Brady, M.; Smith, S. Segmentation of brain MR images through a hidden Markov random field model and the expectation-maximization algorithm. IEEE Trans. Med. Imaging 2001, 20, 45-57. [CrossRef]

51. Smith, S. Fast robust automated brain extraction. Hum. Brain Mapp. 2002, 17, 143-155. [CrossRef]

52. Patenaude, B.; Smith, S.M.; Kennedy, D.N.; Jenkinson, M. A Bayesian model of shape and appearance for subcortical brain segmentation. Neuroimage 2011, 56, 907-922. [CrossRef] [PubMed]

53. Andersson, J.; Smith, S.; Jenkinson, M. FNIRT-FMRIB's non-linear image registration tool. In Proceedings of the 14Th Annual Meeting of the Organization for Human Brain Mapping (OHBM), Melbourne, Australia, 15-19 June 2008.

54. Basser, P.; Mattiello, J.; LeBihan, D. MR diffusion tensor spectroscopy and imaging. Biophys. J. 1994, 66, 259-267. [CrossRef]

55. Veraart, J.; Sijbers, J.; Sunaert, S.; Leemans, A.; Jeurissen, B. Weighted linear least squares estimation of diffusion MRI parameters: Strengths, limitations, and pitfalls. Neuroimage 2013, 81, 335-346. [CrossRef] [PubMed]

56. Westin, C.-F.; Maier, S.; Mamata, H.; Nabavi, A.; Jolesz, F.; Kikinis, R. Processing and visualization for diffusion tensor MRI. Med. Image Anal. 2002, 6, 93-108. [CrossRef]

57. Dhollander, T.; Raffelt, D.; Connelly, A. Unsupervised 3-tissue response function estimation from single-shell or multi-shell diffusion MR data without a co-registered T1 image. In Proceedings of the ISMRM Workshop on Breaking the Barriers of Diffusion MRI, Lisbon, Portugal, 11-16 September 2016.

58. Tournier, J.D.; Calamante, F.; Connelly, A. Robust determination of the fibre orientation distribution in diffusion MRI: Non-negativity constrained super-resolved spherical deconvolution. Neuroimage 2007, 35, 1459-1472. [CrossRef] [PubMed]

59. Rolls, E.T.; Huang, C.-C.; Lin, C.-P.; Feng, J.; Joliot, M. Automated anatomical labelling atlas 3. Neuroimage 2020, 206, 116189. [CrossRef] 
60. Pauli, W.M.; Nili, A.N.; Tyszka, J.M. A high-resolution probabilistic in vivo atlas of human subcortical brain nuclei. Sci. Data 2018, 5, 180063. [CrossRef]

61. Pietsch, M.; Raffelt, D.; Dhollander, T.; Tournier, J.-D. Multi-Contrast Diffeomorphic Non-Linear Registration of Orientation Density Functions. In Proceedings of the ISMRM 25th Annual Meeting \& Exhibition, Honolulu, HI, USA, 22-27 April 2017; p. 3522.

62. Raffelt, D.; Tournier, J.-D.; Fripp, J.; Crozier, S.; Connelly, A.; Salvado, O. Symmetric diffeomorphic registration of fibre orientation distributions. Neuroimage 2011, 56, 1171-1180. [CrossRef]

63. Raffelt, D.; Tournier, J.-D.; Crozier, S.; Connelly, A.; Salvado, O. Reorientation of fiber orientation distributions using apodized point spread functions. Magn. Reson. Med. 2012, 67, 844-855. [CrossRef]

64. Patriat, R.; Cooper, S.E.; Duchin, Y.; Niederer, J.; Lenglet, C.; Aman, J.; Park, M.C.; Vitek, J.L.; Harel, N. Individualized tractography-based parcellation of the globus pallidus pars interna using 7T MRI in movement disorder patients prior to DBS surgery. Neuroimage 2018, 178, 198-209. [CrossRef]

65. Tournier, J.-D.; Calamante, F.; Connelly, A. Improved Probabilistic Streamlines Tractography by 2nd Order Integration over Fibre Orientation Distributions. In Proceedings of the 2010 ISMRM Annual Meeting, Stockholm, Sweden, 1-7 May 2010.

66. Calamante, F.; Tournier, J.-D.; Jackson, G.D.; Connelly, A. Track-density imaging (TDI): Super-resolution white matter imaging using whole-brain track-density mapping. Neuroimage 2010, 53, 1233-1243. [CrossRef] [PubMed]

67. Theisen, F.; Leda, R.; Pozorski, V.; Oh, J.M.; Adluru, N.; Wong, R.; Okonkwo, O.; Dean, I.D.C.; Bendlin, B.B.; Johnson, S.C.; et al. Evaluation of striatonigral connectivity using probabilistic tractography in Parkinson's disease. Neuroimage Clin. 2017, 16, 557-563. [CrossRef] [PubMed]

68. Bertino, S.; Basile, G.A.; Bramanti, A.; Anastasi, G.P.; Quartarone, A.; Milardi, D.; Cacciola, A. Spatially coherent and topographically organized pathways of the human globus pallidus. Hum. Brain Mapp. 2020, 41, 4641-4661. [CrossRef] [PubMed]

69. Bertino, S.; Basile, G.A.; Anastasi, G.; Bramanti, A.; Fonti, B.; Cavallaro, F.; Bruschetta, D.; Milardi, D.; Cacciola, A. Anatomical Characterization of the Human Structural Connectivity between the Pedunculopontine Nucleus and Globus Pallidus via Multi-Shell Multi-Tissue Tractography. Medicina 2020, 56, 452. [CrossRef] [PubMed]

70. Haber, S.N. The primate basal ganglia: Parallel and integrative networks. J. Chem. Neuroanat. 2003, 26, 317-330. [CrossRef] [PubMed]

71. Haber, S.; Kunishio, K.; Mizobuchi, M.; Lynd-Balta, E. The orbital and medial prefrontal circuit through the primate basal ganglia. J. Neurosci. 1995, 15, 4851-4867. [CrossRef] [PubMed]

72. Draganski, B.; Kherif, F.; Klöppel, S.; Cook, P.A.; Alexander, D.C.; Parker, G.J.M.; Deichmann, R.; Ashburner, J.; Frackowiak, R.S.J. Evidence for Segregated and Integrative Connectivity Patterns in the Human Basal Ganglia. J. Neurosci. 2008, 28, 7143-7152. [CrossRef]

73. Milardi, D.; Quartarone, A.; Bramanti, A.; Anastasi, G.; Bertino, S.; Basile, G.A.; Buonasera, P.; Pilone, G.; Celeste, G.; Rizzo, G.; et al. The Cortico-Basal Ganglia-Cerebellar Network: Past, Present and Future Perspectives. Front. Syst. Neurosci. 2019, 13, 61. [CrossRef]

74. Chung, H.-W.; Chou, M.-C.; Chen, C.-Y. Principles and Limitations of Computational Algorithms in Clinical Diffusion Tensor MR Tractography. Am. J. Neuroradiol. 2010, 32, 3-13. [CrossRef]

75. Cacciola, A.; Bertino, S.; Basile, G.A.; Di Mauro, D.; Calamuneri, A.; Chillemi, G.; Duca, A.; Bruschetta, D.; Flace, P.; Favaloro, A.; et al. Mapping the structural connectivity between the periaqueductal gray and the cerebellum in humans. Brain Struct. Funct. 2019, 224, 2153-2165. [CrossRef]

76. Gradin, V.B.; Kumar, P.; Waiter, G.; Ahearn, T.; Stickle, C.; Milders, M.; Reid, I.; Hall, J.; Steele, J.D. Expected value and prediction error abnormalities in depression and schizophrenia. Brain 2011, 134, 1751-1764. [CrossRef] [PubMed]

77. Koch, K.; Schachtzabel, C.; Wagner, G.; Schikora, J.; Schultz, C.; Reichenbach, J.R.; Sauer, H.; Schlösser, R.G. Altered activation in association with reward-related trial-and-error learning in patients with schizophrenia. NeuroImage 2010, 50, 223-232. [CrossRef] [PubMed]

78. Laruelle, M.; Kegeles, L.S.; Abi-Dargham, A. Glutamate, Dopamine, and Schizophrenia. Ann. N. Y. Acad. Sci. 2003, 1003, 138-158. [CrossRef] [PubMed]

79. Alba-Ferrara, L.; De Erausquin, G.A. What does anisotropy measure? Insights from increased and decreased anisotropy in selective fiber tracts in schizophrenia. Front. Integr. Neurosci. 2013, 7, 9. [CrossRef] 
80. Lee, S.-H.; Kubicki, M.; Asami, T.; Seidman, L.J.; Goldstein, J.M.; Mesholam-Gately, R.I.; McCarley, R.W.; Shenton, M.E. Extensive white matter abnormalities in patients with first-episode schizophrenia: A diffusion tensor imaging (DTI) study. Schizophr. Res. 2013, 143, 231-238. [CrossRef] [PubMed]

81. Nakamura, K.; Kawasaki, Y.; Takahashi, T.; Furuichi, A.; Noguchi, K.; Seto, H.; Suzuki, M. Reduced white matter fractional anisotropy and clinical symptoms in schizophrenia: A voxel-based diffusion tensor imaging study. Psychiatry Res. Neuroimaging 2012, 202, 233-238. [CrossRef]

82. Kelly, S.; Jahanshad, N.; Zalesky, A.; Kochunov, P.; Agartz, I.; Alloza, C.; Andreassen, O.A.; Arango, C.; Banaj, N.; Bouix, S.; et al. Widespread white matter microstructural differences in schizophrenia across 4322 individuals: Results from the ENIGMA Schizophrenia DTI Working Group. Mol. Psychiatry 2018, 23, 1261-1269. [CrossRef]

83. Alexander, A.L.; Lee, J.E.; Lazar, M.; Field, A.S. Diffusion tensor imaging of the brain. Neurotherapeutics 2007, 4, 316-329. [CrossRef]

84. Winston, G.P. The physical and biological basis of quantitative parameters derived from diffusion MRI. Quant. Imaging Med. Surg. 2012, 2, 254-265.

Publisher's Note: MDPI stays neutral with regard to jurisdictional claims in published maps and institutional affiliations.

(C) 2020 by the authors. Licensee MDPI, Basel, Switzerland. This article is an open access article distributed under the terms and conditions of the Creative Commons Attribution (CC BY) license (http://creativecommons.org/licenses/by/4.0/). 